\title{
La estructura dramática en TV: una fórmula para atrapar a la audiencia
}

\section{Carmen Gloria López}

Periodista por la Universidad Católica de Chile, Master en Periodismo por la Universidad de Maryland at College Park [carmenglorialopez@mail.com].

Los procedimientos usados en ficción pueden mejorar la atención, la memoria y la comprensión de las noticias televisivas. La estructura dramática disminuye la complejidad del mensaje y, al hacerlo, reduce el esfuerzo cognitivo que se demanda a los telespectadores. De ello resultaría una mejor memoria elaborada. Cuarenta sujetos participaron en un experimento de mediciones repetidas (repeated measures) en el que vieron cuatro historias de un noticiario. Las noticias en versión dramática tuvieron mayores niveles de comprensión y mejor recordación que aquellas en versión 'periodística' (pirámide invertida). ${ }^{1}$

- orprende la escasa atención académica que - recibe el proceso cognitivo ligado a la estructura de la información periodística. Al contrario de los educadores, quienes también trabajan con el traspaso de contenidos, los periodistas y comunicadores damos poca importancia, en el día a día, a los códigos que deben seguir los mensajes que queremos traspasar.

Estar informado no es sólo recibir datos, es asimilarlos y entenderlos. En ese contexto, han resultado profundamente preocupantes todos los estudios que hablan de poca retención y comprensión de las noticias televisivas. A pesar ellos, ${ }^{2}$ y de los descubrimientos en el campo de la sicología cogni 


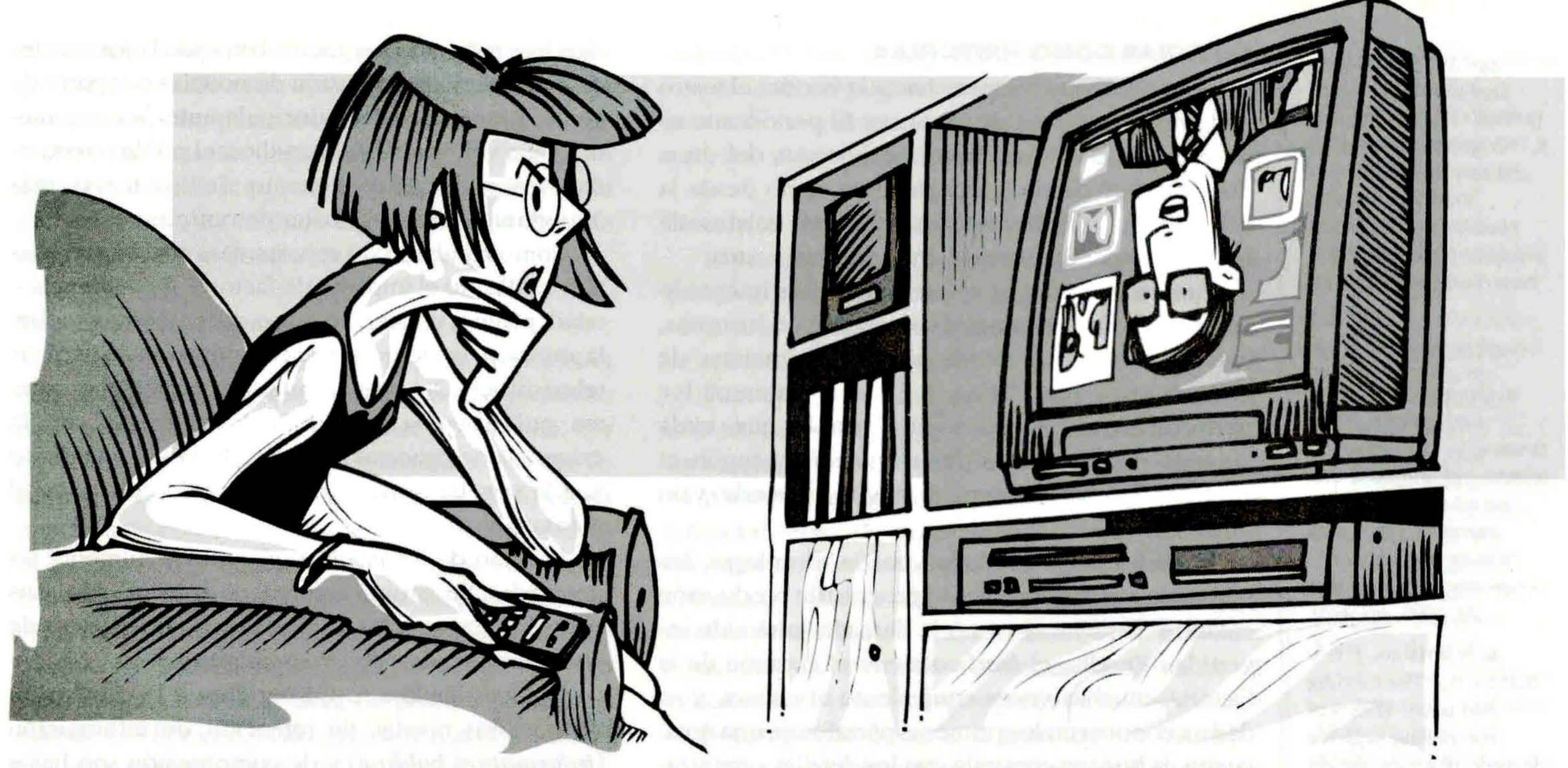

tiva que señalan la importancia de la estructura de una historia para el procesamiento de la información, ${ }^{3}$ pocos periodistas televisivos piensan en sus audiencias en estos términos a la hora de realizar sus notas. Los esfuerzos se concentran más bien en capturar al público, lo que se traduce en darle importancia a los leads o ganchos.

Es cierto que esta discusión ya es parte de algunos programas de periodismo como el de la Universidad Católica, pero pocos -aún hoy-se han centrado en entender el porqué de esta relación entre la estructura de una historia y su procesamiento. Esto motivó el estudio que se presenta aquí. Es un esfuerzo por constatar si, en efecto, la estructura dramática funciona para aquello que más importa al periodismo: la comprensión del contenido que se transmite.

La primera pregunta para esta investigación era: ¿Ayuda la estructura dramática a mejorar la entrega informativa, es decir, a que se logre la comprensión final de los hechos? Y la segunda iba dirigida a las razones de ello: ¿Qué sistemas utilizamos para procesar información que podrían verse afectados o ayudados por la forma en que estructuramos un mensaje? En el fondo: ¿Por qué sirve la estructura dramática? $\mathrm{O}$, ¿̨por qué no?

Las respuestas a la segunda pregunta se encuentran principalmente en el área de la educación y la sicología cognitiva, donde los profesionales sí han tratado de definir cómo traspasar mejor -es decir, con mayores índices de memoria y comprensiónlos contenidos educativos. Sin embargo, los estudios en el área periodística -de la no ficción en general y de la televisión en particular-son muchos menos.

$\mathrm{Al}$ momento de plantearse esta investigación, lo poco que se había hecho en esta materia se enfocaba en los efectos en atención, comprensión y memoria de ciertos aspectos específicos de la TV como las imágenes, ${ }^{4}$ los cortes en la edición, ${ }^{5}$ las imágenes impactantes, ${ }^{6}$ los mensajes visuales versus el audio $^{7}$ y el uso de bumpers y teasers en los noticiarios. 8

Pocos 9 habían investigado el modo en que el orden de los elementos dentro de una historia afecta la comprensión y recordación de noticias, objetivo de este estudio.
1. Este artículo es la síntesis de la tesis de magister publicada por Camen Gloria López en 1995 en la Universidad de Maryland at College Park y las observaciones que ella ha agregado luego de trabajar cinco años en la estructuración de reportajes de larga duración.

2. Graber, D.: "Seeing is remembering: How visuals contribute to the learning from news", Journal of Communication 40, 1990, pp. 134155.

3. MEADOWCROFT, J. y REEvEs, B.: "Children's attention to television: The influence of story schema development on allocation of mental effort and memory", Communication Research 16, 1989, 
pp. 352-374. El tema también se discute en BOWER, G. H. y CIRILO, R K.: "Cognitive psychology and text processing", en

VAN DIJK, T. (ed.) Handbook of discourse analysis, Academic Press, New York, 1985, pp. 71-

4. GRABER, D.: op. cit.

5. GEIGER, S., LANG, A. STRICKWERDA, M., y SUMNER, J.: "The effects of related and unrelated cuts on television viewers' attention, processing capacity and memory", Communication Research 20, 1993, pp. 4-29.

6. Newhagen, J. E. y ReEves, B.: "The evening bad news: Effects of compelling negative television news images on memory", Journal of Communication 42(2), 1992, pp. 25-41.

7. CRIGLER, A., JUST, M. y NEUMANN, W.: Interpreting visual vs. audio messages in television news (en imprenta durante la investigación).

8. Cameron, G., SchleuDER, J. Y WHITE, A. "Priming effects of television news bumpers and teasers on attention and memory", Journal of Broadcasting and Electronic Media, 1993, pp. $437-452$.

9. FINDAHL, O. y HOJJER, B.: "Studies of news from the perspective of human comprehension", en WILHOIT, G.C. Y DE BOCK, H. (eds.): Mass Communication Review Yearbook 2,

Sage, Beverly Hills, CA, 1981, pp. 393-403. Ver

\section{NOTICIAS COMO HISTORIAS}

No es extraño que miremos hacia la ficción, el teatro y el drama en busca de fórmulas. El periodismo es un ejercicio de contar historias, historias del día a día, reales. Y desde la imaginación como desde la realidad, los resultados son similares: relatos de hechos traspasados desde un individuo a otro.

Pero en la práctica el periodismo ha intentado escapar de sus orígenes de contador de historias, haciendo esfuerzos extremos por diferenciarse de otras formas dramáticas. ${ }^{10}$ En este intento, los periodistas han creado una fórmula que viola algunas reglas básicas del story-telling, según el cual las historias tienen un principio, un medio y un final. ${ }^{11}$

Históricamente limitados por la tecnología, los periodistas estandarizaron el proceso de producción creando estructuras como la llamada "pirámide invertidan. En ella, el lead contiene el corazón de la historia, muchas veces equivalente al clímax, y es dado a conocer en los primeros párrafos de una nota. Luego, la historia continúa con los detalles organizados de acuerdo con su relevancia, de mayor a menor.

Aunque las audiencias mostraron por años una preferencia por la ficción sobre el contenido real, muchos noticiarios televisivos aún entregan información en estas crónicas "invertidas". ${ }^{12} \mathrm{El}$ ritmo de trabajo, el miedo a salirse del esquema común y la poca comprensión de los hechos por los mismos periodistas empujan a los reporteros de TV a mantener estas fórmulas que requieren menor análisis y más rapidez. Son modos más parecidos a las crónicas de un periódico antiguo que al drama de una obra de teatro.

Por eso, al observar la nota de un noticiario muchas veces parece que estuviéramos viendo una película desde el final hacia el principio. El hecho de experimentar un relato televisivo al revés podría estar obstaculizando significativamente la comprensión de ese mensaje.

\section{RECORDAR Y COMPRENDER LAS NOTICIAS EN TELEVISIÓN}

Aunque la televisión ha superado distancias y fronteras a través de diversas tecnologías, muchos estu- dios han mostrado y siguen mostrando bajos niveles de memoria y comprensión de noticias por parte de gente que se informa principalmente por ese medio. ${ }^{13}$ En varios de estos estudios, el público recuerda menos del 50 por ciento de los temas más importantes de una semana de noticias.

Como resultado de eso, muchas investigaciones han analizado el impacto de factores de audiencia edad, género, educación, y uso de los medios-sobre la atención, la memoria y la comprensión de noticias televisivas. ${ }^{14}$ Otros estudios sugieren que el problema radica en la complejidad del medio, en la exigencia de procesar un estímulo visual y auditivo $y$, a la vez, tratar de darle un sentido coherente al mensaje. ${ }^{15}$

El ritmo de los noticiarios también aumenta las demandas de procesamiento de información. Las notas son breves y las audiencias no son capaces de controlar información en esos lapsos. ${ }^{16}$

La investigadora Ann Lang llega a la conclusión de que "los niveles de retención de información (information bolding) y de comprensión son bajos porque la cantidad de esfuerzo que los telespectadores invierten al ver TV no es suficiente para procesar completamente un noticiario". ${ }^{17}$ En otras palabras, el éxito en la elaboración de la información está determinado por la capacidad del espectador y por la complejidad del mensaje. ${ }^{18}$

$\begin{gathered}\text { Calidad de la elaboración } \\ \text { de la información }\end{gathered}=\frac{\begin{array}{c}\text { Capacidad cognitiva } \\ \text { del telespectador }\end{array}}{\text { Complejidad del mensaje }}$

Si esto es cierto, incapaces de mejorar las capacidades cognitivas de la audiencia, los periodistas televisivos podemos mejorar la memoria y comprensión de nuestros mensajes al reducir la complejidad de ellos, estructurando historias en una forma que sea más fácil de procesar. ${ }^{19}$

\section{ESTRUCTURA DE UNA HISTORIA Y EL PROCESAMIENTO DE NOTICIAS EN TV}

Numerosos estudios demuestran cómo la organización dentro de un mensaje puede aumentar o disminuir la calidad del procesamiento de éste. Concuerdan en que la estructura dramática afecta fuertemente la manera en que la audiencia procesa, 
recuerda y comprende la información. ${ }^{20}$ Sin embargo, la mayoría de estas investigaciones se ha hecho para textos y no para contenidos televisivos.

Hay otras teorías cognitivas que también ayudan a comprender la importancia de la estructura en el procesamiento de noticias televisivas. Una de ellas es la teoría del esquema (schema theory).

\section{Teoría del esquema}

La teoría del esquema es una gran proposición teórica para describir cómo las audiencias procesan noticias de televisión. ${ }^{21}$ De acuerdo con ella, los espectadores tienen ciertas expectativas cuando se sientan a ver TV, expectativas que se basan en su experiencia con el medio y con otras formas narrativas. Usan estas expectativas -llamadas schematacomo un modo de ahorrar recursos de procesamiento. Lo que hacen es anticipar nueva información basándose en la antigua. Cuando un mensaje se arma de esta forma, la tarea de procesarlo se hace más fácil. 22 Por ello, si las características estructurales de un mensaje son usadas de modo inapropiado, se daña su memorización y comprensión.

El esquema, entonces, guía la atención del receptor y es el modelo a través del cual la audiencia interpreta la estructura de una historia y su mensaje. ${ }^{23}$

Varios resultados apoyan la idea de que estas estructuras de memoria o esquemas de procesamiento favorecen la comprensión al interrelacionar el conocimiento del espectador en el mismo momento en que procesa información nueva. ${ }^{24}$ Mientras mayor es la identificación de la estructura del mensaje con el esquema mental del telespectador, mayor es la probabilidad de comprensión de esas historias. ${ }^{25}$ Los textos "deformes" o las "historias revueltas" aumentan el esfuerzo de procesamiento y resultan en niveles menores de recordación que aquellos textos que se acercan al esquema ideal. ${ }^{26}$

\section{Memoria semántica y episódica}

El procesamiento de los mensajes involucra una compleja red de funciones cognitivas. La memoria semántica y la memoria episódica están en las bases de ese procesamiento.

Para que una información pase a ser parte de nuestro conocimiento general, primero necesita estar integrada a nuestra memoria episódica, la memoria para eventos, detalles y situacionales de orden temporal. Sólo después de que procesamos una información y creamos una lista de conceptos para comenzar a elaborarla, esta subgráfica de conocimiento puede pulirse y almacenarse en la memoria semántica. La memoria semántica actúa sobre el conocimiento preexistente y juega un rol importante en la comprensión, como el gran tesauro mental.

Como la comprensión de un mensaje depende de lo bien que se transfiera la memoria episódica a la memoria semántica, ${ }^{27}$ la fuerza que tenga la memoria episódica es clave para que el conocimiento pase a ser semántico. A su vez, la fuerza de la memoria episódica depende de la intensidad y la relevancia de la experiencia, del grado de compromiso emocional con la experiencia comunicativa y con su orden temporal.

De estos resultados se puede deducir dos nociones importantes para los periodistas de TV:

- Primero, que para mejorar la comprensión y memorización de las historias, éstas deben estar estructuradas de modo que el telespectador no también: LANG, A.: "Effects of Chronologica presentation of informa tion on processing and memory for broadcast news", Journal of Broadcasting and Electronic Media 33, 1989. pp. $441-452$.

10. BIRD, S. y DARDENNE, R.: "Myth, chronicle and story: Exploring the narrative qualities of news", en CAREY, J. (ed.): Media, myths and narratives: Television and the press, Sage, London, 1988, pp. 67-86. Ver también: CuRTIN, M. "Packaging reality: The influence of fictional forms on the early development of television documentary", Journalism Monographs $n^{\circ} 137$, Association for Education in Journalism and Mass Communication, Columbia, 1993

11. Por razones de espacio, se obvió una explicación en profundidad de los elementos básicos de la estructura dramática. La mejor referencia de éstos y su aplicación al periodismo televisivo está en PUENTE, S.: El drama becho noticia, Ediciones Universidad Católica, Santiago, 1997.

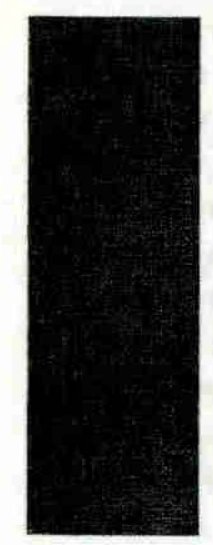

ncapaces de mejorar las capacidades cognitivas de la audiencia, los periodistas televisivos podemos mejorar la memoria y comprensión de nuestros mensajes al reducir la complejidad de ellos, estructurando historias en una forma que sea más fácil de procesar. 
12. Ver BIRD, S. $y$ DARDENNE, R., op. cit. y LANG, ANN, op. cit.

13. Davis, D. K. y ROBINSON, J. P.: "Comprehension of a single evening's news", en ROBINSON, J.P; I.EVY, M.R.;

DAVIS, D.K.; WOODALL,

W.G.; GUREvTTCH, M y SAHIN, H. (eds.): The main source: learning from television news, The

Publishers of Professional Social Science, Beverly Hills, 1986, pp.107-132. Ver también WOODALL. W.; DAVIS, D.; y SAHAIN, H.: "From the boob tube to the black box: TV news comprehension from an information processing perspective", Journal of Broadcasting 27, 1983, pp. 1-23.

14. Ibid.

15. GEIGER, S. y REEVES, B.: "The effects of scene changes and semantic relatedness on attention to television”, Communica-

tion Research 20, 1993, pp. 155-175.

16. GRABER, D.: op. cit.

17. LANG, A., op. cit.

18. Newhagen, J.: "Effects of censorship disclaimers in Persian Gulf war television news on memory and thought elaboration", Communication Research 21, 1994, pp. $232-248$.

19. LANG, A., op. cit

20. BOWER y CIRILO, op. cit.; GEIGER y REEVES, op. cit ; GEIGER, LANG, STRICKWERDA Y SUMNER, op. cit.; WOODALL, op. cit.

21. Bower y Cirilo, op cit:; MFADOWCROFT y necesite acceder a su memoria semántica para la comprensión. Así, se reduce la complejidad del mensaje y el esfuerzo demandado al receptor. Por lo tanto, debería aumentar la memoria y comprensión.

Una solución en este sentido es la que propone Lang: escribir noticiarios en orden cronológico. De esta manera, afirma, las audiencias pueden ver los eventos como ocurren, reconstruyendo las causas y consecuencias de tiempo real, ahorrándose el esfuerzo de acceder a su memoria semántica. El problema es que las historias noticiosas no siempre tienen un orden cronológico. Muchas noticias hacen referencia a procesos que pueden ser paralelos o eventos que se desarrollaron en forma simultánea o sin relación temporal. 28

La solución, entonces, pareciera estar más bien en un diseño episódico basado en relaciones causales, en el cual la cronología esté dada no por el tiempo sino en términos de eventos causa-efecto ligados por un objetivo común. Dentro de una historia, el origen de estas causas y sus consecuencias implica cambios en el statu quo, movimiento y un grado de conflicto implícito en cualquier cambio.

Al dar cuenta del contexto y al presentar claramente a los actores de una historia, se debería ahorrar al espectador el acceso a los nódulos de la red semántica lo que, como se ha dicho, distrae de la información entrante. En este diseño, el corazón de la historia debe quedar para el final, después de que las causas y los personajes han sido expuestos.

- La segunda deducción es que si la transferencia de memoria episódica a semántica depende de su fuerza y ésta, a su vez, de la relevancia y fuerza de la experiencia, los periodistas deberían buscar la manera de involucrar al telespectador intensamente en el relato. Una estructura que relata el contexto y logra empatía con los protagonistas de una historia tiene más posibilidades de involucrar al receptor con la entrega informativa.

La tensión inherente a la estructura dramática construida alrededor de un conflicto- no sólo debería hacer las historias más fáciles de comprender, sino que debería crear mayores niveles de compromiso y de atención, lo que a su vez debería mejorar la memoria y la comprensión.

En resumen, los descubrimientos de la sicología cognitiva sugieren que el buen resultado de la estructura dramática en ficción tiene fundamentos en el modo en cómo se procesa la información y, del mismo modo, la estructura dramática debería mejorar la memoria y comprensión de las noticias.

\section{MEDICIÓN DE LA TEORIAA}

El desafío en el presente estudio era comprobar esta teoría en la práctica. Se tomaron tres variables independientes: atención, memoria y comprensión. La variable dependiente fue la estructura de la historia. Las posibilidades eran que fuera una

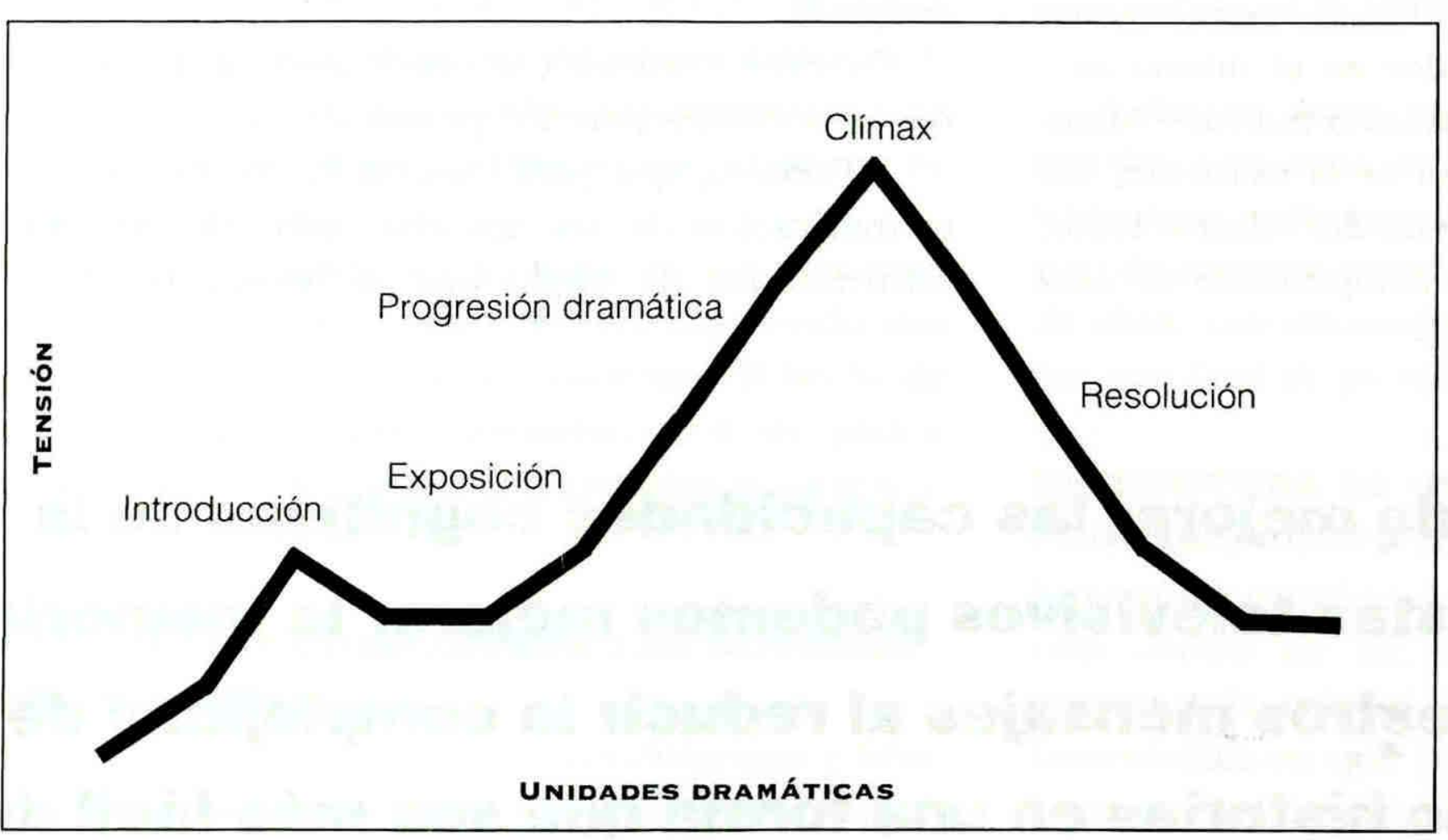

FIGURA O: LA CURVA

DRAMÁTICA, TÍPICA DE GRAN PARTE DE LAS OBRAS DE FICCIÓN, PUEde APLICARSE A LA ESTRUCTURACIÓN DE LAS NOTICIAS. A MEDIDA QUE EL RELATO AVANZA, CRECE LA TENSIÓN HASTA QUE SE LLEGA A UN PUNTO MÁXIMO EN EL CLÍMAX, LUEGO DEL CUAL SE ALCANZA UN NUEVO EQUILIBRIO. 


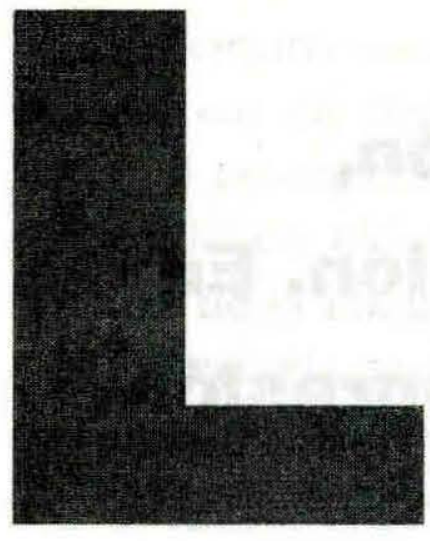

\section{a mayoría de las historias clasificadas tendían a entregar información climática al comienzo de la historia. Es decir, entregaban primero la consecuencia de un evento o la resolución del conflicto y luego las causas y el contexto.}

estructura de pirámide invertida o una estructura dramática. El experimento se basó en las siguientes hipótesis:

1. Para la variable atención: La variable atención a través de las historias variará dependiendo de la estructura de ellas.

$\mathrm{H}_{1 \mathrm{a}}$ Las historias con estructura dramática mostrarán una curva dramática a lo largo de la historia, alcanzando su punto máximo de atención en el clímax (Figura 0).

$\mathrm{H}_{1 \mathrm{~b}}$ Las historias con estructura de pirámide invertida mostrarán una curva descendiente de atención a lo largo de la historia.

2. Para la variable memoria:

$\mathrm{H}_{2 \mathrm{a}}$ Las historias dramáticas tendrán mayores niveles de reconocimiento de claves (cued recognition) para información en la narrativa que las uinvertidas".

$\mathrm{H}_{2 \mathrm{~b}}$ Las noticias dramáticas tendrán niveles de recordación de imagen más altos que las de pirámide invertida.

3. Para la variable comprensión:

$\mathrm{H}_{3}$ Las noticias con estructura dramática tendrán niveles de comprensión más altos que las historias "invertidas".

Métodos: Este fue un expermiento $2 \times 1$ factorial de diseño de medidas repetidas (repeated mesaures design). El factor fue la estructura de la historia y sus niveles fueron: dramática o pirámide invertida. La exposición a las distintas versiones fue manipulada entre sujetos.

Sujetos: Participaron 46 estudiantes de la Universidad de Maryland at College Park. Tenían un rango de edad entre los 17 y 42 años. Cada sujeto vio dos historias de las dos condiciones, o sea, dos dramáticas $\mathrm{y}$ dos invertidas.

Material: Se grabaron 7 horas de noticias de las cadenas $C N N, A B C$ y $C B S$ para elegir las noticias que servirían de estímulo. Se codificó y analizó el contenido de veinte historias de acuerdo con las siguientes categorías: relaciones causales, tipo de información y tensión. Esto fue hecho para comprobar la existencia de estructura invertida y la presencia de tipos de información que pudieran ser clasificados dentro de las unidades temáticas de la estructura dramática: introducción, exposición, progresión dramática, clímax y resolución.

Los resultados de este breve análisis de contenido demostraron que los elementos causales están ausentes de las noticias en la mayoría de los casos y que una historia está formada de partes que pueden ser clasificadas de acuerdo con el nivel de tensión o conflicto que ellas presentan. La mayoría de las historias clasificadas tendían a entregar información climática al comienzo de la historia. Es decir, entregaban primero la consecuencia de un evento o la resolución del conflicto (como el número de víctimas en un caso de accidente) y luego las causas y el contexto.

Finalmente, se seleccionaron cuatro historias que cumplían con los requisitos. Los criterios para elegirlas fueron:

1. que la narrativa incluyera elementos de causa y efecto que pudieran ser manipulados;

2. que la historia incluyera algún tipo de información que se considerara clímax; y

3. que el resto de la información en la historia pudiera ser clasificado como introducción, exposición, progresión, clímax o desenlace.

Al seleccionarse sólo aquello que potencial-
REEVES, op. cit.; MEADOWCROFT Y WATT, op. cit.; WOODALL, op. cit.

22. GEIGER, S. y REEVES, B., op. cit.

23. MEADOWCROFT, J. y ReEves, B., op. cit.

24. SмIтH, F.M., "The effects of story structure training upon first grader's memory and comprehension of wordless picture books", disertación doctoral no publicada, Universidad de Maryland, 1986.

25. MEADOWCROFT, J. y REEVES, B., op. cit.

26. BOWER, G.H., y CiRILO, R.K., op. cit.

27. LANG, op. cit.

28. FINDAHL, O. y HOIJER, B., op. cit. 


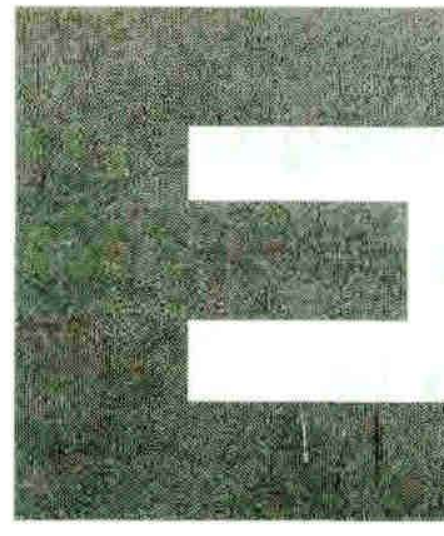

\section{n las historias dramáticas, el orden era: introducción, exposición, progresión dramática, clímax y resolución. En las de pirámide invertida, la secuencia era: clímax, progresión dramática, exposición, introducción y resolución.}

mente podía llamarse historia, se dejaron fuera noticias que consistían sólo en declaraciones oficiales o citas sueltas.

Preparación del estímulo: El siguiente paso fue crear dos versiones diferentes de estas cuatro historias. Primero se identificó el principal conflicto de ellas. Luego se dividieron en segmentos: introducción, exposición, progresión, clímax y resolución. La clasificación consideró tanto elementos de la narrativa como de las imágenes. Luego estos cinco segmentos fueron reorganizados. En el caso de los segmentos expositivos, se les agregó un gráfico que enfatizaba su función de exposición con los principales puntos dados en esa unidad temática.

En la edición final, las dos versiones de cada historia contaban con la misma narrativa, las mismas imágenes y la misma duración. Lo único que variaba era el orden de estas unidades temáticas. En las historias dramáticas, el orden era: introducción, exposición, progresión dramática, clímax y resolución. En las llamadas de pirámide invertida, la secuencia era: clímax, progresión dramática, exposición, introducción y resolución.

Cada cinta de estímulo contenía seis historias. Al comienzo, había una para probar el equipamiento y para que el sujeto se acostumbrara a la atmósfera y los instrumentos. La segunda historia -seguida de una tanda comercial- era para aumentar la naturalidad del experimento. Luego venían las cuatro historias-estímulo, cada una de las cuales duraba aproximadamente dos minutos y era presentada en pantalla por un título que sugería su tema. Éstos eran: $E l$ derecho de una madre, Un show aéreo inolvidable, Otro pueblo de Bosnia y Los camioneros marcharán.

El orden de las historias fue aleatorio en las cuatro cintas para evitar un posible efecto de éste en los resultados.

Variables dependientes: Como se ha dicho, las variables dependientes en este estudio fueron atención, memoria y comprensión. La atención fue medida como el tiempo de reacción para una tarea secundaria. La memoria, como reconocimiento de imágenes y de datos de la narrativa. El nivel de comprensión fue medido de dos maneras: la habilidad de resumir el punto principal de una noticia y la habilidad de narrar en orden dramático los eventos en preguntas de respuesta abierta.

\section{a) Atención}

Mientras los sujetos miraban las noticias en pantalla debían apretar un botón cada vez que oían un tono. Había diez tonos distribuidos en cada historia, uno al comienzo y otro al final de cada unidad temática.

El tiempo de reacción para esta tarea secundaria fue utilizado como indicador del nivel de atención que los sujetos ponían a las noticias. Mientras más alto fuera el tiempo de reacción grabado en el archivo computacional, mayor atención estaba poniendo el sujeto al estímulo principal: las noticias. ${ }^{29}$

\begin{abstract}
b) Memoria
Una segunda cinta de once minutos fue editada para medir reconocimiento de imágenes (memoria visual). Esta cinta tenía 137 segmentos de video sin audio. Cada segmento duraba 0,4 segundos y estaba separado del siguiente por 4,5 segundos de un pantallazo negro. Este material visual se seleccionó de cada unidad temática (una imagen por unidad) y el resto eran segmentos de comerciales e imágenes que el sujeto no había visto.
\end{abstract}


La memoria visual fue medida por el tiempo que demoraban en responder (es decir, en apretar el botón al reconocer una imagen). El menor tiempo registrado en el computador indicaba una mayor latencia de la imagen en la memoria del sujeto. ${ }^{30}$

La memoria para la narrativa fue medida con un cuestionario de veinte preguntas de alternativa sobre datos entregados en la historia.

\section{c) Comprensión}

El nivel de comprensión fue medido con preguntas de respuesta abierta usando un esquema de codificación que favorece el reconocimiento del tema central de una historia. Los puntajes iban desde 0 (recordar una historia distinta) hasta 8 (recordar el punto central de una historia y ,además, tres o más detalles importantes). El límite de comprensión en esta escala fue el puntaje 5 (recordación del punto central de la historia).

Otro elemento utilizado para medir la calidad de la comprensión fue pedirle a los sujetos que, en uno o dos párrafos, volvieran a contar la historia que habían visto. La línea de historia seguida en el recuento se evaluó con una escala que codifica los elementos de narrativa presentes en las respuestas y premia el establecimiento de relaciones causa-efecto. Ésta va de 0 (no recuerda nada) hasta 7 (es capaz de establecer relaciones causales e identifica protagonistas y antagonistas).

\section{RESULTADOS}

\section{A) ATENCIÓN Y ESTRUCTURA DRAMÁTICA}

Se confirmó la hipótesis de que la atención en las historias depende de la estructura. La FIgURA 1 muestra dos curvas de atención distintas para la misma historia según su estructura.

La hipótesis de que la curva de atención seguiría la curva de tensión de la estructura dramática fue confirmada en parte porque hubo un alza no esperada en el tiempo de reacción al tono ubicado después de la gráfica en la exposición. Lo mismo ocurrió con la hipótesis de que la atención decaería durante la noticia construida en pirámide invertida. El tiempo de reacción de los espectadores disminuyó a lo largo de la historia con la sola excepción ante el tono posterior al gráfico, lo que deforma en parte la curva.

Al hacer el análisis por unidad temática también se ve un aumento en el tiempo de reacción ante el tono ubicado después del gráfico. Esto podría explicarse porque el gráfico requiere mayor esfuerzo de procesamiento de información por parte del sujeto $y$, por lo tanto, su reacción a un estímulo secundario es más lenta.

En ambos casos, eso sí, el tiempo de reacción para el estímulo secundario fue mayor durante el clímax, lo que muestra un efecto de la unidad temática en el tiempo de reacción.

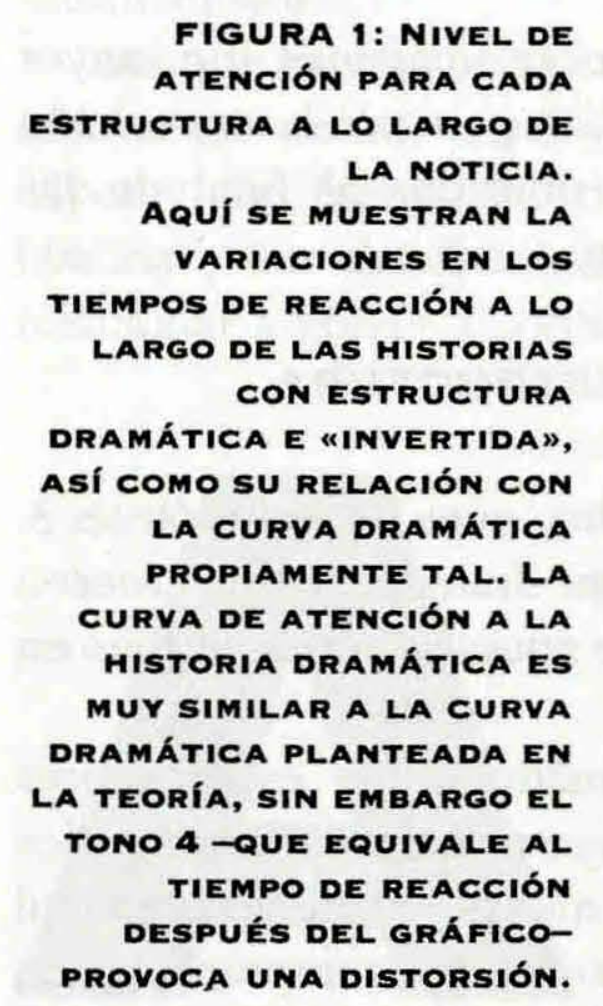

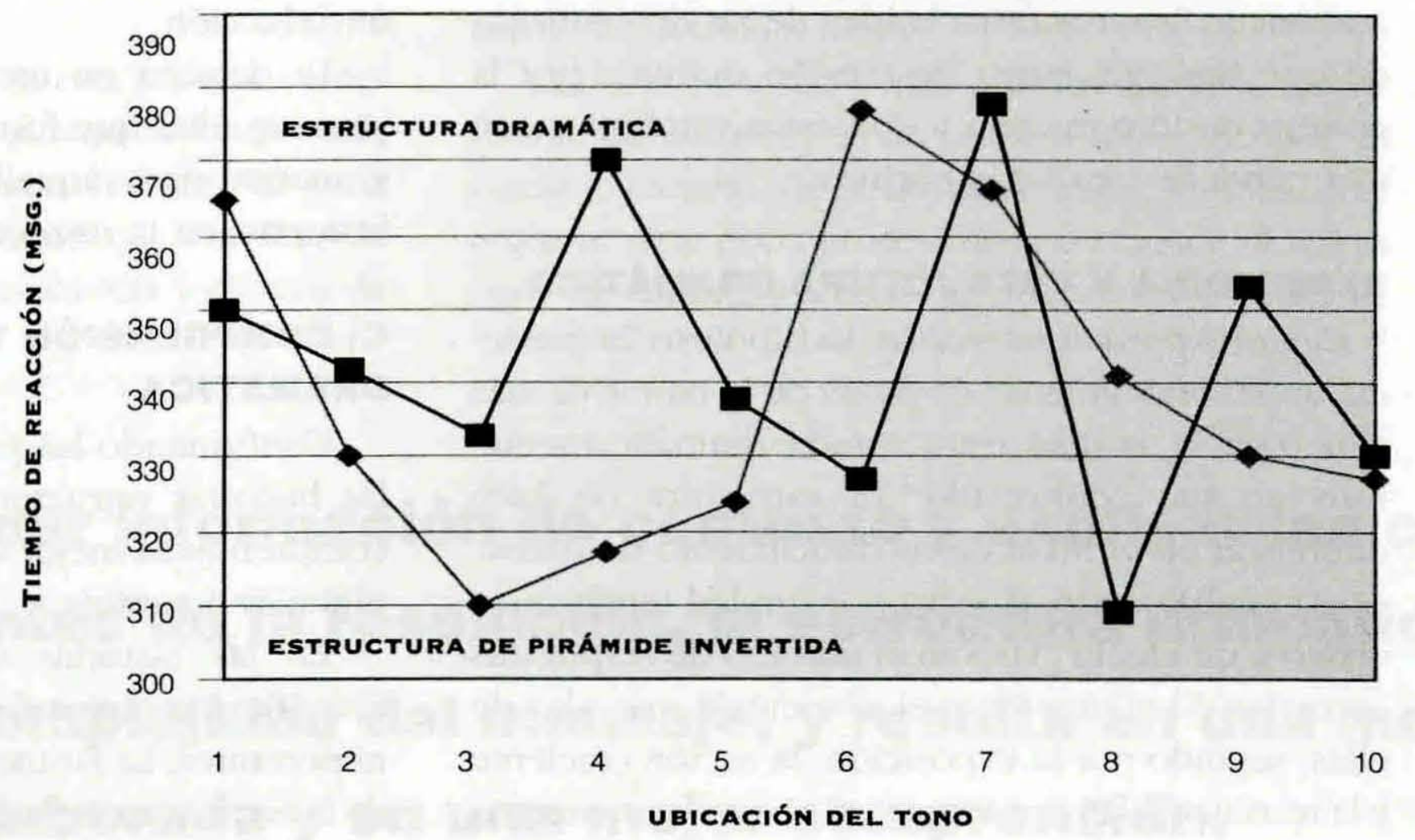

30. NEWHAGEN, J. E. y REEVES, B., op. cit. 


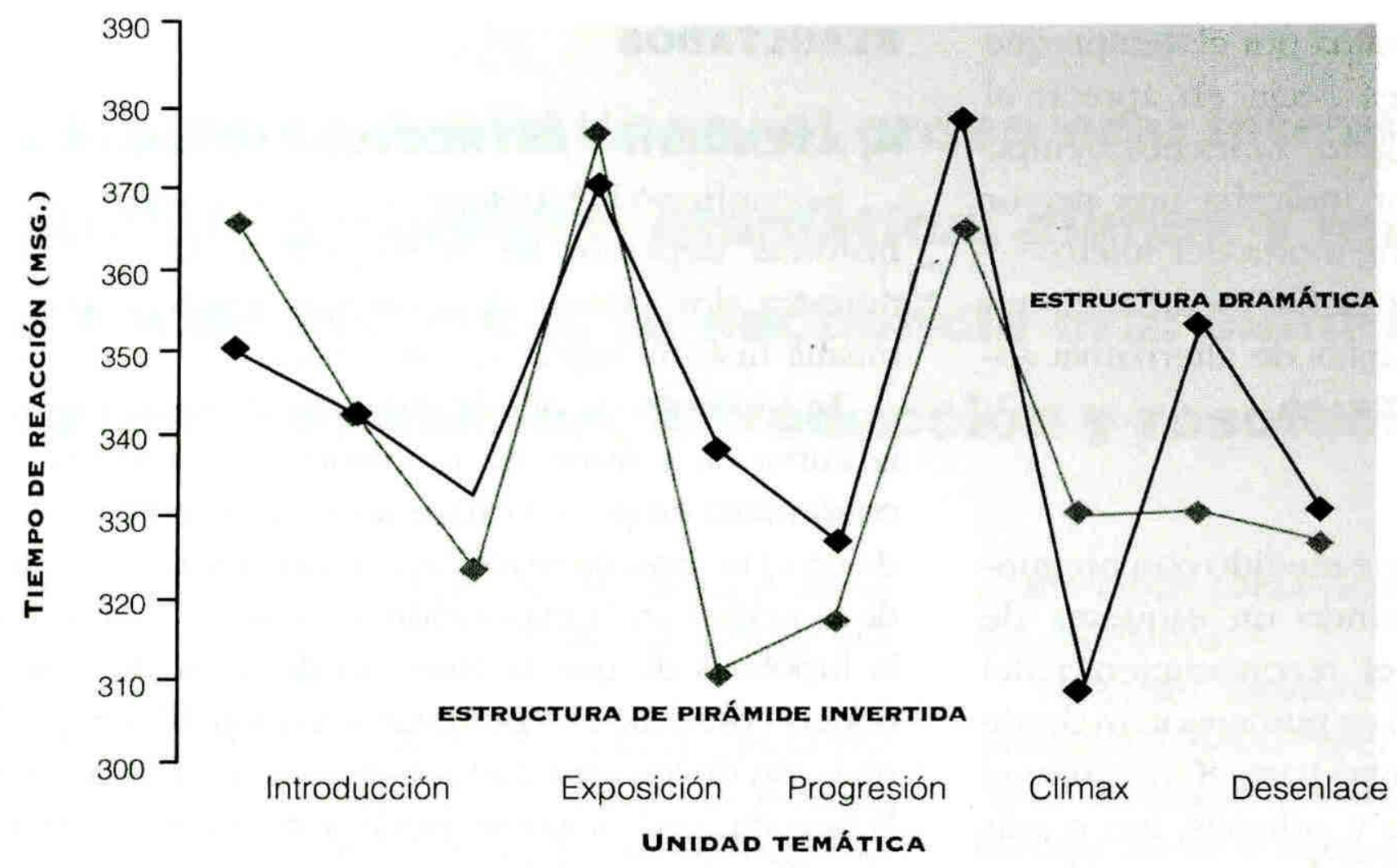

FIGURA 2: NIVELES DE ATENCIÓN POR UNIDAD TEMÁTICA.

AQUí SE MUESTRA LA CURVA DE ATENCIÓN POR UNIDAD TEMÁTICA. SE OBSERVAN SIMILITUDES CON LA TEORÍA DRAMÁTICA: EL CLÍMAX ES EL QUE OBTIENE MAYOR ATENCIÓN, DESPUÉS DE LA EXPOSICIÓN QUE ESTÁ DISTORSIONADA POR LA REACCIÓN AL GRÁFICO.

Con la excepción del segundo tono de la exposición, al hacer el análisis por unidad temática, la curva es muy parecida a la propuesta para la estructura dramática: la atención aumenta en el momento de la introducción del conflicto, baja un poco al comienzo de la exposición y comienza a aumentar hacia el clímax para decaer fuertemente durante la resolución (FIGURA 2).

Lo anterior sugiere que el tipo de información que contiene cada una de las unidades temáticas sí marca una diferencia en el nivel de atención de la audiencia. Esto confirma la idea de los dramaturgos de que hay una curva de tensión definida por la entrega de información y que estos cambios crean una curva de tensión específica.

\section{B) MEMORIA Y ESTRUCTURA DRAMÁTICA}

- Memoria para la narrativa. La hipótesis 2a predecía un reconocimiento de datos de la narrativa más alto para la noticia estructurada dramáticamente. Esto no fue confirmado. La estructura no hizo diferencia en el nivel de reconocimiento de datos.

Al analizar este aspecto por unidad temática se observa un efecto claro en el número de respuestas correctas. El clímax tuvo el porcentaje más alto de ellas, seguido por la exposición, la acción creciente y la resolución. El porcentaje más bajo de respuestas correctas fue para los datos de la introducción. En resumen, la unidades temáticas sí influyeron en el recuerdo de datos aún cuando el orden en que éstas se presentaron no tuvo efecto.

- Memoria para las imágenes. La estructura no tuvo efecto sobre la cantidad de imágenes reconocidas por los sujetos. Sin embargo, de nuevo hubo consecuencias en el análisis por unidad temática. Las imágenes de la resolución fueron las más reconocidas por la mayor parte de los sujetos, seguidas de las imágenes de la acción creciente, el clímax y la introducción.

La demora en reconocer imágenes fue mayor para aquellas que formaban parte de la exposición y menor para aquellas ubicadas al final de las historias, en la resolución.

\section{C) COMPRENSIÓN Y ESTRUCTURA DRAMÁTICA}

Confirmando las predicciones de la hipótesis 3, las historias estructuradas dramáticamente fueron comprendidas mejor que aquellas estructuradas en pirámide invertida.

En las historias dramáticas, los espectadores identificaron mejor el punto principal y más detalles importantes. La FIGURA 3 muestra el efecto principal de la estructura de la historia en la comprensión. En 


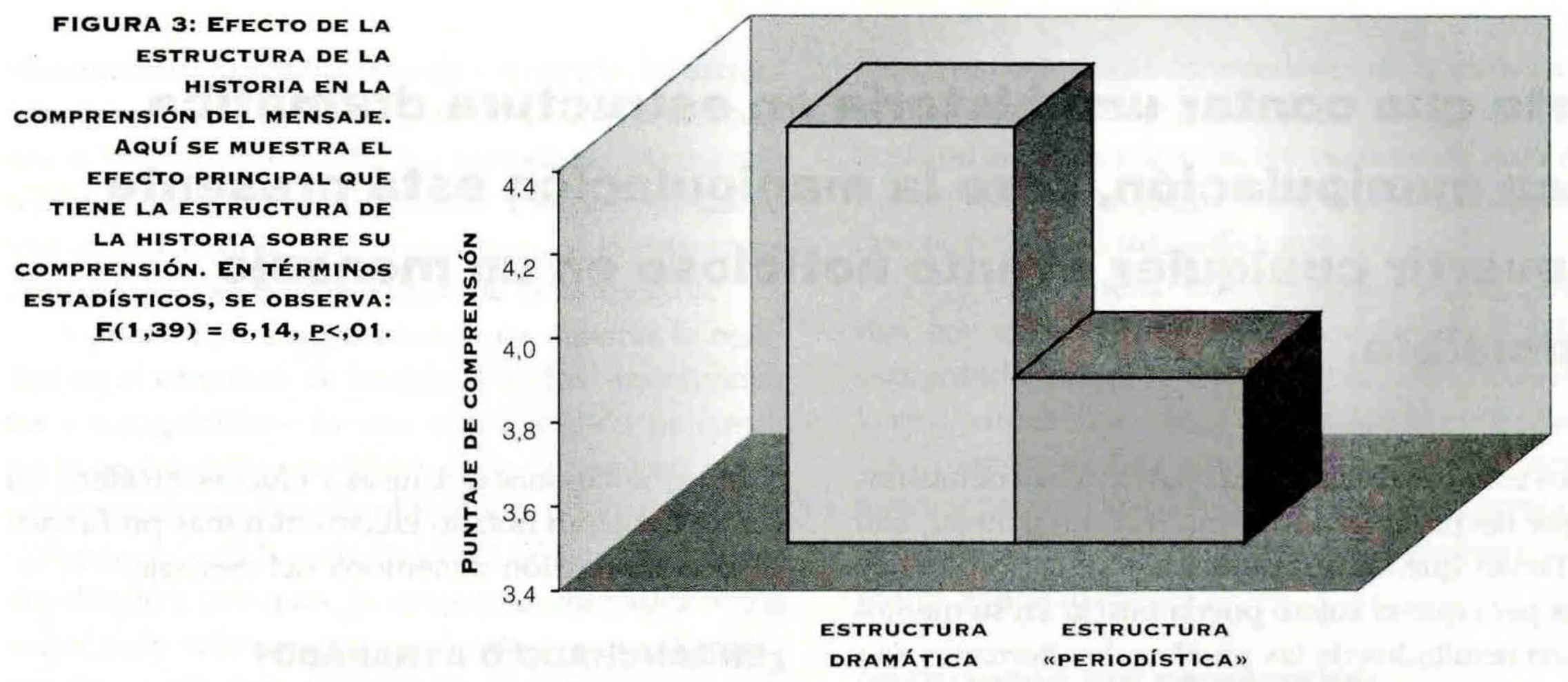

la escala de 0 a 8 , las noticias dramáticas tuvieron un nivel promedio de 4,4 de comprensión y las de pirámide invertida un 3,8 .

De 160 respuestas de comprensión -4 historias por 40 sujetos- 61 obtuvieron un puntaje de 5 o más. De estas $61,59 \%$ correspondió a noticias dramáticas y $40,9 \%$ a noticias en pirámide invertida.

Este efecto también es evidente en la línea dramática de las respuestas. Cuando los sujetos narraban las historias dramáticas de nuevo, lo hacían con una línea más coherente y lógica de retransmisión.

Aunque las dos versiones de una historia contenían la misma información, los sujetos fueron más capaces de identificar el punto central de una historia y sus detalles importantes y, a la vez, de relacionar y volver a contar las causas y efectos de un evento cuando la noticia estaba estructurada dramáticamente.

\section{DISCUSIÓN FINAL}

Los resultados indican que la estructura afectó especialmente los niveles más altos de procesamiento. No influyó en la memoria para imágenes o datos concretos contenidos en la narrativa, pero sí en la comprensión más profunda de una noticia y la capacidad de establecer relaciones de causa y efecto entre los hechos al punto de poder relatar nuevamente la historia a otros.

La razón para esto podría estar en que el reconocimiento de imágenes es un proceso manejado por un estímulo externo, de abajo hacia arriba, en el cual se requiere muy poco procesamiento y donde el sujeto tiene claves claras y precisas para buscar en su memoria.

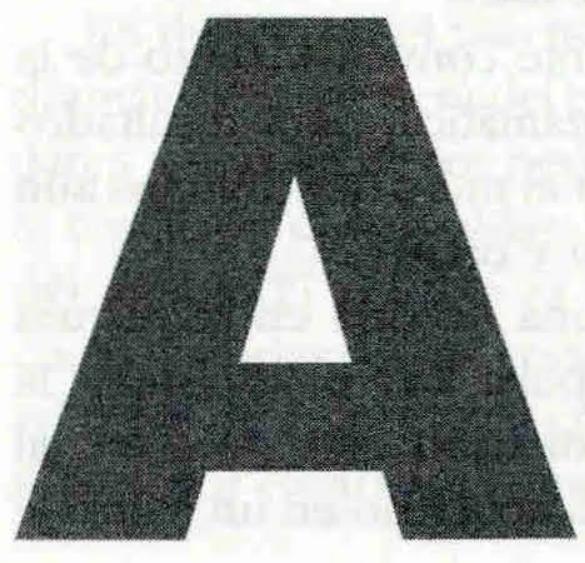

I dar información de contexto y explicar las causas antes de la resolución, la estructura dramática reduce la complejidad del mensaje, y resulta en una memoria más elaborada y en una mejor comprensión. 


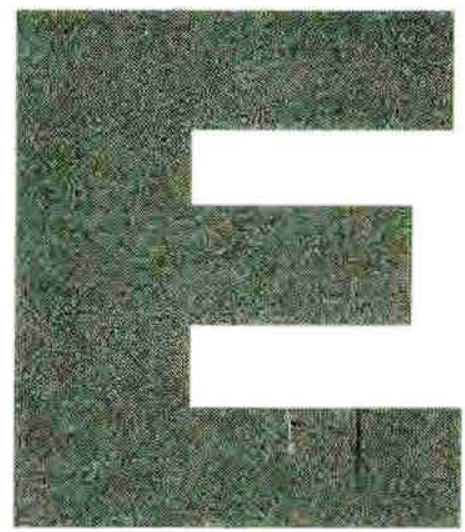

\section{s cierto que contar una historia en estructura dramática} implica manipulación, pero la manipulación está presente al convertir cualquier evento noticioso en un mensaje

\section{transmisible.}

31. ANDERSON, J.: Cognitive Psychology and its implications, Freeman, New York, 1985.

32. GRABER, D., op. cit.
Los estudios de sicología cognitiva han demostrado que las pruebas de alternativas, en general, son más fáciles que las de respuesta abierta porque hay pistas para que el sujeto pueda buscar en su memoria. Los resultados de las pruebas de alternativa son normalmente mejores. ${ }^{31}$ Lo mismo puede haber ocurrido con la memoria para datos presentados en el test de alternativas.

Sin embargo, los efectos de la estructura se observan de manera relevante en los niveles más altos del procesamiento de la información, cuando a los telespectadores se les pidió recordar y volver a contar la historia de una noticia. La reproducción de las historias dramáticas fue más precisa y completa que las de pirámide invertida. Esto sugiere que al dar información de contexto y explicar las causas antes de la resolución, la estructura dramática reduce la complejidad del mensaje y resulta en una memoria más elaborada y en una mejor comprensión.

Aunque los niveles de comprensión en general son bajos -tema para otro estudio-, en la mayoría de los casos, cuando los individuos comprendieron el punto central de la historia, ésta estaba construida dramáticamente.

Es muy importante recordar que este aumento en la comprensión fue producido por el mero reordenamiento de las unidades temáticas. Para reducir todos los efectos no relacionados con el orden de las unidades, el diseño experimental sólo manipuló eso. Esta precaución hace más válidos los resultados del estudio, pero obviamente reduce las diferencias teóricas entre estructura dramática y pirámide invertida. Si se hubieran trabajado todos los elementos de la teoría dramática: conflicto, tratamiento de prota- gonistas/antagonistas, causas y efectos, etcétera, tal vez se hubieran notado efectos aún más profundos en la comprensión y memoria del mensaje.

\section{¿ENGANCHADO O ATRAPADO?}

Los resultados de este experimento hacen dos contribuciones fundamentales a la discusión inicial.

Primero, que la curva dramática, lo que en teoría se ha asumido como real, sí existe en términos de atención. El clímax es el punto donde los espectadores están más envueltos y más atentos a la historia.

Segundo, que los encargados de las noticias no debieran preocuparse porque la estructura dramática no parta con el gancho o clímax. Las historias en pirámide invertida muestran una curva descendente tan pronto como los telespectadores conocen la información del clímax el comienzo. Esto confirma los resultados de Graber $^{32}$ de que la audiencia de noticias pierde el interés después del inicio o lead.

Al contrario, la estructura dramática crea una curva de atención más estable y ascendentè, en la que no sólo engancha al telespectador sino que lo atrapa. Esta idea de "atrapar" a la audiencia implica compromiso y emoción, variables de gran atractivo para la investigación futura.

\section{DESAFÍOS PROFESIONALES}

Aunque hay un creciente convencimiento de la utilidad de la estructura dramática, estos resultados deberían ayudar a derribar el muro que algunos aún levantan entre periodismo y drama.

Es cierto que contar una historia en estructura dramática significa manipular los datos, pero la manipulación de la información está presente al convertir cualquier evento noticioso en un mensaje 
transmisible, ya sea en pirámide invertida, en estructura dramática o como un punteo de datos. Sea cual sea la estructura elegida, los periodistas damos a la realidad un orden que no tenía. Los periodistas no transmiten noticias, las construyen, y la estructura dramática es sólo otro patrón de construcción.

Algunos han argumentado que mostrar la realidad en el esquema de buenos y malos -protagonistas y antagonistas- es una simplificación peligrosa de la realidad, ${ }^{33}$ pero la estructura dramática no es necesariamente esa simplificación hollywoodense. Comparada con la estructura del "qué, cómo, cuándo, dónde y por quén, la estructura dramática relata mejor y de manera más profunda eventos y procesos, poniendo énfasis en las causas y los efectos y en los personajes que forman parte de ellos.

Cualquier recuento de la realidad, cualquier intento de reducir hechos al papel o a imágenes de TV, resultará siempre en un producto más simple y pobre que la realidad misma, porque está limitado por el espacio y el tiempo. Esta simplificación comienza en el mismo lugar de los hechos cuando parte de lo que ocurre es contado de una persona a otra.

La dramatización -el uso de la estructura dramática para contar un evento noticioso-, por lo tanto, no es algo poco ético. Dramatizar noticias no significa exagerar un conflicto, sino enfatizarlo en términos de los factores que mueven a los seres humanos a actuar y reaccionar. Quizás el principal obstáculo para hacer esto es la complejidad de aplicar el drama a la realidad. Un periodista no puede crear personajes, ni "limpiar" un conflicto de sus aristas complejas como sí puede hacerlo un guionista de cine. Además, en la realidad, el periodista suele desconocer el desenlace de la historia.

En definitiva, el uso no abusivo de la estructura dramática dependerá del profesionalismo, los estándares y la ética de los periodistas de TV para frenar la tentación de "amoldar" la realidad a los patrones del drama. El consejo es simple: mirar las noticias como historias con un comienzo, un medio y un final en lugar de comenzar a contarlas por su desenlace. No es, por cierto, un consejo fácil de seguir porque requiere periodistas conocedores de la información de contexto, investigadores de las motivaciones profundas de sus personajes y capaces de identificar los conflictos en juego en eventos que parecen desconectados e insignificantes.

Pero vale la pena: no sólo haría mejores noticiarios per se, sino que ayudaría a las audiencias a comprender mejor lo que está pasando, a conectar lo que parece desconectado, a mirar eventos diarios como procesos. La dramatización debería, incluso, mejorar las comunicaciones al hacer las narraciones interpersonales de las noticias más precisas, coherentes y atractivas.

\section{PREGUNTAS SIN RESPUESTA: INVESTIGACIÓN FUTURA}

Para disminuir al máximo el error estadístico este estudio fue, como se ha explicado, purista en su medición. Sólo se modificó el orden de los elementos de las historias y sólo se midió ese impacto. Futuros estudios podrían analizar el efecto del tema específico de una noticia sobre estas mismas variables. Quizás, las estructura dramática funciona mejor para cierto tipo de temas y no para otros. Un segundo aspecto no investigado es el impacto de los otros atributos de la estructura dramática: presencia y ausencia de personajes identificables, de conflicto, de tensión, etcétera.

El objetivo de la tragedia es despertar emociones. $\mathrm{Al}$ construir tensión y suspenso el drama involucra a la audiencia, "atrapándola" en la historia. Esto hace que los espectadores se "enamoren" de los personajes antes de que éstos se enfrenten a una crisis. Este atributo esencial del drama -el despertar emociones- tampoco fue investigado en esta tesis y sería un punto de gran interés al aplicar estructura dramática a las noticias. ¿Cómo influye la estructura dramática sobre las emociones? ¿Eleva el ritmo cardíaco de la audiencia? ¿Cómo afecta este compromiso emocional al procesamiento del mensaje? ¿Estar "atrapado" por una historia afecta la racionalidad? ¿Mejora el traspaso de información?

Hay miles de preguntas pendientes sobre cómo mejorar el procesamiento de la información periodística
33. MCGRAIL, A. y MILBURN, M.: "The dramatic presentation of news and its effects on cognitive complexity", Political Psychology, 13 , 1992, pp. 613-632. 